International Research Journal of Management, IT \& Social Sciences
Available online at https://sloap.org/journals/index.php/irjmis/
Vol. 7 No. 3, May 2020, pages: 22-28
ISSN: 2395-7492
https://doi.org/10.21744/irjmis.v7n3.884

\title{
Level of Characterization Development Reached by Santiago Badmintonists in Decision Making
}

Amaya Castillo Caurel ${ }^{\text {a }}$

Article history:

Submitted: 27 January 2020

Revised: 09 February 2020

Accepted: 18 March 2020

\section{Keywords:}

badmintonists; characterization; decision making; sports psychology;

\begin{abstract}
The act of deciding is considered one of the current research problems of Sports Psychology. It is important to know what athletes think, how they analyze game situations and how they make decisions during vital moments of obtaining a satisfactory sporting result. The decision-making guarantees, then, the rapid adaptation of the athlete to emergent situations of training and competition. Badminton as a sport of high strategy demands in those who practice it, perceptual, decisive and execution skills. From a descriptive study, having as sample six badmintonists from Santiago, it is intended to characterize the level of development reached by the latter in decision making. Techniques such as the memory stimulation interview, coach interviews and the game performance evaluation instrument (GPAI) are used as an observation protocol. The present characterization shows that in training and competition, badmintonists present difficulties in the perceptual-cognitive, decisive and executive indicators of the decision process. They also reveal the technical-methodological limitations of the coach in the development of the said process in his athletes.
\end{abstract}

International research journal of management, IT and social sciences ()$^{2} 2020$. This is an open access article under the CC BY-NC-ND license (https://creativecommons.org/licenses/by-nc-nd/4.0/).

Corresponding author:

Amaya Castillo Caurel,

Universidad de Oriente, Santiago de Cuba, Cuba.

Email address: amaya.castillo@nauta.cu 
1 Introduction

Over the past decades, interest in gaining greater knowledge about the factors that influence the achievement of high athletic performance has been increasing. This fact has caused that any professional related to the sports world, has needed asking questions such as: what psychological variables determine at a specific competitive moment, the performance is good or bad ?, How do professionals guarantee linked to sport, that the athlete obtains an adequate sports performance in the competition?

Sports performance is based on four fundamental domains: physiological, technical-tactical, psychological and cognitive, being included in the latter the specific knowledge of the sport and the ability that a player has to determine which option is the most appropriate in a given situation (Janelle \& Hillman, 2003). The practice of sports characterized by the rapid and precise adaptation in time deficit to a dynamic and changing environment, demands from the players a series of perceptual, decisive and execution capacities, which are determining factors of sports performance.

Badminton as an individual opposition sport or as an adversary sport, although in the case of double modalities it could be included in cooperation-opposition sports, also called team, a mini team of two people, (Grunenfelder $e$ t al., 1998) referred to by Hair et al. (2000). Likewise, it requires cognitive operations that allow us to anticipate and evaluate what may, or may not happen, because it is difficult for the same actions to be repeated, by trying 2 so that the opponent knows as little as possible how we will act (Ruiz, 1994) referred to by Cabello (2000). This discipline is characterized by the continuous action of intervals of action, pause and the incessant decision making by the player (Hair, 2000).

The use of game actions based on each situation in the search for success requires producing mental decisions, which need to receive and develop information. A player can have very good technique (perfectly execute all the blows) however, not make good decisions when choosing which stroke or displacement is appropriate depending on where his opponent is and himself. With training, like the technical-tactical element, this decision-making must be very fast, is improved and you learn to take the initiative in the points and be more efficient. In the course of a badminton match, the pace of the actions is fast and changing, therefore, it is necessary to perceive the situations that arise in the game, with great clarity. The decisions must be correct, at the expense of the short time available, in the same way, the actions have to be precise.

The act of deciding is considered as one of the current research problems in disciplines such as Psychology, Education and Sports Sciences. These last ones constitute a fertile ground to investigate this matter since it constitutes a mystery to know what the athletes think, how they analyze the game situations and how they make the decisions in moments of vital importance for obtaining a satisfactory sporting result. For sports psychology, it is a topic of great interest in recent decades. In the study of sports performance Ruiz \& Sánchez (1997), have performed analyzes of the different processes that are involved in sports performances, and have highlighted the role of cognitive processes involved in decision making (Williams et al.,1999).

The first studies on decision-making in sport were carried out in laboratory conditions in which it was tried to reproduce situations, which, although distant from the reality of the sport, involved perceptual-cognitive processes relevant to sport (Bar-Eli \& Raab, 2006; Bard \& Fleury, 1976; Alain \& Proteau, 1980; Goulet et al. 1989), referred to by Ruiz \& Graupera (2010). Similarly, studies have been carried out on the visual patterns of athletes (Goulet et al. 1989), the analysis of the structure of knowledge that athletes possess and use when deciding (French \& Thomas, 1987) or the study of the employment of the relevant perceptual signals in racket sports (Abernethy, 1991) among others.

In short, attention has been focused on perceptual-cognitive processes to know how to use the information, how to treat it and as a consequence, how to decide in situations of varying degrees of demand. However, decision making is an activity that develops under cognitive and emotional aspects. So that a decision in the game is influenced, on the one hand, by the cognitive and rational involvement of the player in terms of selecting relevant information from the game environment, assessing possible options, choosing the action to be executed, and the possibility of change during the first phase of execution (Konzag, 1992), and on the other hand, for aspects related to emotional, volitional and motivational.

Taking into account the cognitive perspective of decision-making, it can be affirmed that great efforts have been made to try to demonstrate which elements can be more determinant of this aspect, finding works focused on the stages of information processing that are in the basis of the decision-making process, cognitive strategies based on working memory and knowledge structure, as well as other approaches that suggest that decision-making derives from anticipation processes (Bar-\& Raab, 2006).

The study of decision making from the perspective of Ecological Psychology can be approached from various points of view and theories, although the most used is developed by Gibson (Araújo \& Davids, 2009). Ecological

Caurel, A. C. (2020). Level of characterization development reached by Santiago badmintonists in decision making. International Research Journal of Management, IT and Social Sciences, 7(3), 22-28. 
psychology focuses on the interaction of the individual with their environment, expressed in the coordination and control of movement (García-González et al., 2011).

In Cuba, studies related to decision-making have been directed based on the tactical performance of karatekas (Lores, 2010), team management in table tennis (Díaz, 2011) and basketball (Robles, 2014), related to the perceptual visual training in table tennis (Hernández, 2012), with the tactical preparation of the athlete (Romero, 2013), with sports intelligence in the fighting teams (Hernández, 2017) as well as volitional quality to be perfected in handball athletes (Naples \& Neyra, 2018). The aforementioned authors have analyzed the decision process from several directions and with different objectives, however, in the Cuban reality, it continues without proposing solid arguments that support the training of this cognitive process linked to badminton as a high-strategy sport.

Currently, there are numerous lines of research that work from more dynamic approaches, aspects related to decision making. It is real that the most relevant research, in sport, has been based on Cognitive Psychology and Ecological Psychology (García-González et al., 2011), although, in essence, both of them pursue the fundamental objective of understanding, understand and explain the decision process. For this study, the author will focus on the decision-making process from the integration of concepts and indicators defined by both the cognitive and ecological paradigms, taking into account their points of convergence and the objective pursued by both approaches.

Considering these antecedents, a preliminary diagnosis was made to explore the main problems existing during sports training. This initial search revealed that athletes: do not always properly choose the type of movement or technical ability to execute in response to a given game situation; they rarely manage to anticipate the intentions of the opponent to gain an advantage in the game; slowdown in decision making (taking into account the speed of the game and the shortage of time to execute the correct action); they present difficulties in technical execution and are intuitive, without control over decision-making). On the other hand, in the Comprehensive Athlete Preparation Program (20132018), decision-making training does not require actions that are directly related to its implementation. Besides, sports trainers suffer from theoretical-methodological tools to face the decision-making process of their athletes with creativity and assertiveness (Smith, 2003; Smith \& Sparkes, 2009; Swann et al., 2015; Smith \& Sparkes, 2009). It is imperative to characterize the level of development achieved by badmintonists in decision making.

\section{Materials and Methods}

The present study is descriptive, non-experimental and transversal, where the author describes how the phenomenon is and manifests, observing it in its natural context. It also defines, controls and manipulates indicators to diagnose existing problems. We work with a sample of six badmintonists from the Santiago EIDE selected from an intentional non-probabilistic sampling technique, constituting one hundred percent of the universe to study.

The theoretical level methods used were: the analytical-synthetic, the inductive-deductive and the structural systemic for the elaboration of the theoretical-methodological assumptions that support the decision-making process in sport. In the same way, methods of the empirical level are used such as:

a) Semi-structured Interview I (coach) to know their assessment of the fundamental elements that make up the decision making of badmintonists.

b) Semi-structured Interview II (coach) with the objective of know their assessment of how the indicators of the decision-making process are manifested in the badmintonists who make up the sample during their systematic practice.

c) Structured memory stimulation interview (athletes) to know, after verbalizing the athlete's thinking, the indicators Cognitive that respond to the decision process as well as its manifestations.

A structured interview is carried out to the athlete, applied during the stimulated memory sessions, carried out after viewing the game situations selected for the analysis. It consists of four open questions, each one corresponding to one of the established dimensions, except the dimension referred to the technical-tactical options, on which it is investigated more deeply, proposing two questions.

Registration of game situations:

a) Technological record of the motor behavior of players during a match

b) Selection of technical-tactical actions for further analysis (two success actions and two failure actions)

c) Individual meeting with each athlete to the conduct of the stimulated recall interview

d) Criteria of specialists This technique was used to know the assessment that sports specialists had of the proposed actions developed and with it to make the appropriate adjustments to it for later application 
e) Evaluation instrument of performance in games (GPAI) constitutes an observation protocol, in this case indirect (applied to a recording). Evaluate the player's ability to solve tactical problems, selecting and applying appropriate technical skills.

Game performance components evaluated:

Decision-making: choose the type of movement or skill to be executed in response to a tactical problem. Players consider their position on the court, the position of their opponent and select their shot.

Execution of the skill: after deciding correctly, the execution of the skill must be efficient

Study variable

Decision making: executive thought function, which is conditioned by cognitive and motivational processes in terms of the selection of relevant information game situation and the valuations it makes on the options to be executed and on the adversary (Bharati \& Chaudhury, 2004; Nurmi, 1981; Courtney, 2001; Kim et al., 2008; Aksiana \& Sujana, 2019). It is a process of selecting the alternatives you have, which you consider most appropriate to solve the situation of the game in the shortest possible time.

\section{Dimensions of the variable}

The dimensions of the cognitive variable understudy "decision-making" are perceptual elements of the game environment, the decision-making of technical-tactical action options, execution of the decision taken, evaluation of the decision taken and executed (Iglesias et al., 2002; based on Konzag, 1992) and recorded based on interviews with athletes and coaches.

Perceptual elements of the game environment: (technical-tactical) aspects of the game situation on which the player fixes his attention before making a decision.

Decision making of the technical-tactical action options: It would include the possibilities of action that the player values to execute, having to choose, finally, one of the alternatives proposed for its realization.

Execution of the decision taken: motor execution of the selected tactical alternative.

Evaluation of the decision taken and executed: realization of a personal balance on the effectiveness of the action that the player finally executed.

\section{Results and Discussions}

By integrating the results obtained in each of the instruments applied in the diagnostic stage it can be synthesized that during the development of a Badminton game, whether under the usual training conditions or in the competition, indicators influence perceptual-cognitive, decisive, executive and reflective that allow athletes to select an action within several possibilities. Thus, it is evident that four of the six badmintonists studied present difficulties in making decisions that they make during a game situation. Although they recognize if the game situation is offensive or defensive; in a real game, they go from one to the other unconsciously selecting intuitively, the technical-tactical elements to be used, they notice, only after erring.

By not taking into account perceptual elements of the game environment such as the technical-tactical skills of the adversary, they do not take full advantage of the opportunities to attack him where he shows weakness or foresees his intentions. On the other hand, three athletes present problems when correctly executing the technical elements. Likewise, four of them, not taking into account their abilities, are not very reflective, when evaluating their technicaltactical performance and the tactical effectiveness of the chosen action. Another result to consider is the reference to the existence of causes, apparently external, but that directly affects the process. It is the fact that the coach needs a greater number of methodological tools to train with creativity and assertiveness in the decision-making process of his athletes. Given these shortcomings, the need to develop psycho-pedagogical actions aimed at developing skills and psychological resources that favor the decision-making process in youth badmintonists is emphasized.

Caurel, A. C. (2020). Level of characterization development reached by Santiago badmintonists in decision making. International Research Journal of Management, IT and Social Sciences, 7(3), 22-28. https://doi.org/10.21744/irjmis.v7n3.884 


\section{Conclusion}

The study of the theoretical-methodological assumptions of the process of tactical thinking and decision making in Badminton demonstrates countless contributions, the integration of the cognitive and ecological paradigms being an attempt to make the most of both approaches. .The initial diagnosis revealed the presence of difficulties in perceptualcognitive, decisive, executive and reflexive indicators that allow badmintonists to select an action in a given game situation. Likewise, it is a necessity, to provide the coach with a greater number of methodological tools to train with creativity and assertiveness in the decision-making process of their athletes.

Conflict of interest statement

The author declared that she has no competing interests.

Statement of authorship

The author has a responsibility for the conception and design of the study. The author has approved the final article.

Acknowledgments

I am grateful to two anonymous reviewers for their valuable comments on the earlier version of this paper. 


\section{References}

Abernethy, B. (1991). Visual search strategies and decision-making in sport. International journal of sport psychology.

Aksiana, I. B. W., \& Sujana, I. K. (2019). Effect of Risk Preference, Professional Domination, Information, and Professional Relationship on Ethical Decision Making of Tax Consultants. International Research Journal of Management, IT and Social Sciences, 6(4), 174-179. https://doi.org/10.21744/irjmis.v6n4.675

Alain, C., \& Proteau, L. (1980). Decision making in sport. Psychology of motor behavior and sport, $465-477$.

Araujo, D., \& Davids, K. (2009). Ecological approaches to cognition and action in sport and exercise: Ask not only what you do, but where you do it. International Journal of Sport Psychology, 40(1), 5.

Bard, C., \& Fleury, M. (1976). Analysis of visual search activity during sport problem situations. Journal of Human Movement Studies, 3(2), 214-222.

Bar-Eli, M., \& Raab, M. (2006). Judgment and decision making in sport and exercise: Rediscovery and new visions.

Bharati, P., \& Chaudhury, A. (2004). An empirical investigation of decision-making satisfaction in web-based decision support systems. Decision support systems, 37(2), 187-197. https://doi.org/10.1016/S0167-9236(03)00006-X

Cabello, D. (2000). Analysis of the characteristics of the game in the competition badminton. Its application to training. (Doctoral thesis). University of Granada.

Courtney, J. F. (2001). Decision making and knowledge management in inquiring organizations: toward a new decision-making paradigm for DSS. Decision support systems, 31(1), 17-38. https://doi.org/10.1016/S01679236(00)00117-2

Díaz, J.F. (2011). Proposal of indicators for the decision-making process in the sport of table tennis of the high school of high performance athletes "Cerro Pelado". (Master's Thesis). University of Physical Culture and Sports Sciences "Manuel Fajardo.", Havana City.

French, K. E., \& Thomas, J. R. (1987). The Relation off Knowledge Development to Children's Basketball Performance. Journal of Sport and Exercise Psychology, 9(1), 15-32. https://doi.org/10.1123/jsp.9.1.15

García-González, L., Araújo, D., Carvalho, J., \& Del Villar, F. (2011). An overview of theories and research methods on decision making in tennis. Revista de Psicologia del Deporte, 20(2), 645-666.

Goulet, C., Bard, C., \& Fleury, M. (1989). Expertise differences in preparing to return a tennis serve: A visual information processing approach. Journal of sport and Exercise Psychology, 11(4), 382-398. https://doi.org/10.1123/jsep.11.4.382

Grünenfelder, J., Zünd, G., Prêtre, R., Schmidli, J., Vogt, P. R., \& Turina, M. I. (1998). Right Coronary Artery From Aorto-Left Ventricular Tunnel: Case Report Of A New Surgical Approach. The Journal of thoracic and cardiovascular surgery, 116(2), 363-365.

Hair, J. F., Bush, R. P., \& Ortinau, D. J. (2000). Marketing research: A practical approach for the new millennium. Irwin Professional Publishing.

Hernández, F. (2017). Sports intelligence in men's national wrestling teams in Cuba. (Doctoral thesis). University of Physical Culture and Sports Sciences "Manuel Fajardo“, Havana.

Hernández, R.O. (2012). Perceptual visual training and table tennis an intervention from sports psychology. EF Sports.

Iglesias, G., Hlywka, J. J., Berg, J. E., Khalil, M. H., Pope, L. E., \& Tamarkin, D. (2002). The toxicity of behenyl alcohol: II. Reproduction studies in rats and rabbits. Regulatory Toxicology and Pharmacology, 36(1), 80-85. https://doi.org/10.1006/rtph.2002.1566 Janelle, C. M., \& Hillman, C. H. (2003). Expert performance in sport. Expert performance in sports: Advances in research on sport expertise, 19-47.

Kim, D. J., Ferrin, D. L., \& Rao, H. R. (2008). A trust-based consumer decision-making model in electronic commerce: The role of trust, perceived risk, and their antecedents. Decision support systems, 44(2), 544-564. https://doi.org/10.1016/j.dss.2007.07.001

Konzag, I. (1992). Cognitive activity and player training. Red: sports training magazine , 6 (6), 35-44.

Lores, O. (2010). System of actions to enhance decision-making during the tactical performance of the members of the Karate men's team of the International School of Physical Education and Sports. (Master's Thesis). University of Physical Culture and Sports Sciences "Manuel Fajardo", Havana.

Naples, N., \& Neyra, A. (2018). Decision making: volitional quality to improve in handball athletes. Atlante Magazine: Notebooks of Education and Development.

Nurmi, H. (1981). Approaches to collective decision making with fuzzy preference relations. Fuzzy Sets and systems, 6(3), 249-259. https://doi.org/10.1016/0165-0114(81)90003-8

Ramírez, A.A., Mollinedo, R., Morejón, V., Arencibia, A., Pargas, G., Pons, I., Sánchez, J. (2013-2018). Comprehensive program of preparation of the athlete. Badminton. National Badminton Commission.

Caurel, A. C. (2020). Level of characterization development reached by Santiago badmintonists in decision making. International Research Journal of Management, IT and Social Sciences, 7(3), 22-28. https://doi.org/10.21744/irjmis.v7n3.884 
Robles, R.A. (2014). Sports intelligence actions for the management, during the game of the men's youth basketball team of the Villa Clara province. (undergraduate thesis). University of Physical Culture and Sports Sciences " Manuel Fajardo", Villa Clara.

Romero, G. (2013). Methodology for the tactical group preparation of midfielders in football. (Master's Thesis). University of Physical Culture and Sports Sciences, Camagüey.

Ruiz, E. (1994). Quasi-maximum likelihood estimation of stochastic volatility models. Journal of econometrics, 63(1), 289-306. https://doi.org/10.1016/0304-4076(93)01569-8

Ruiz, L. M., \& Graupera, J. L. (2010). The subjective dimension of decision making in sport development and validity of the cetd questionnaire of sport decision style. European Journal of Human Movement, 14, 95-107.

Ruiz, LM, \& Sánchez, F. (1997). Sports performance. Keys for optimizing learning. Madrid: Gymnos .

Smith, A. L. (2003). Peer relationships in physical activity contexts: A road less traveled in youth sport and exercise psychology research. Psychology of sport and Exercise, 4(1), 25-39. https://doi.org/10.1016/S14690292(02)00015-8

Smith, B., \& Sparkes, A. C. (2009). Narrative analysis and sport and exercise psychology: Understanding lives in diverse ways. Psychology of sport and exercise, 10(2), 279-288. https://doi.org/10.1016/j.psychsport.2008.07.012

Smith, B., \& Sparkes, A. C. (2009). Narrative inquiry in sport and exercise psychology: What can it mean, and why might we do it?. Psychology of sport and exercise, 10(1), 1-11. https://doi.org/10.1016/j.psychsport.2008.01.004

Swann, C., Moran, A., \& Piggott, D. (2015). Defining elite athletes: Issues in the study of expert performance in sport psychology. Psychology of Sport and Exercise, 16, 3-14. https://doi.org/10.1016/j.psychsport.2014.07.004

Williams, A. M., Davids, K., \& Williams, J. G. P. (1999). Visual perception and action in sport. Taylor \& Francis. 